\title{
Serviço Social Postal: Empresa Brasileira de Correios e Telégrafos como um direito fundamental à inclusão
}

\author{
Gabriel Crozetta Mazon ${ }^{1}$ \\ Alcides Goularti Filho ${ }^{2}$
}

\begin{abstract}
RESUMO
A pesquisa analisa quatro políticas públicas, que vem sendo executadas pela Empresa Brasileira de Correios e Telégrafos (ECT), expandindo o enraizamento de sua estrutura de serviços. São quatro serviços prestados pela ECT, estudados pela ótica das políticas públicas. O texto segue dividido em duas partes, começando pela construção de uma trajetória das políticas públicas, partindo do direito fundamental e dos marcos do constitucionalismo moderno, para chegar nas políticas públicas que seguem a lógica de positivação em norma jurídica e a presença do Estado. E, encerrando na análise dos quatro serviços: Caixa Postal Comunitária; Agência de Correio Comunitária; Carta Social; e, Banco Postal. Serviços que foram criados para atender a inclusão social, beneficiando principalmente pessoas antes sem acesso a serviços postais e bancários. Na metodologia se utilizou de referencial bibliográfica, documental e legislação, de caráter exploratório, com abordagem qualitativa e método analítico materialista histórico dialético. Como instrumentos de análise a categoria de adensamento do Estado no território e os conceitos de direito fundamental e políticas públicas. Em meio ao estudo do período recente da ECT (1990-2017), foram encontradas estas quatro políticas públicas e as metas para universalização dos serviços postais. Com a leitura da Carta Anual de Políticas Públicas e Governança Corporativa (2016-2017), alguns relatórios da ECT de acesso online, bibliografias, legislação e demais documentos, se construiu a base da pesquisa. São políticas de institucionalização recente, do último quartel dos anos de 1990 até a atualidade, em processo de aperfeiçoamento e incorporação.
\end{abstract}

Palavras-chave: Serviços Postais, Políticas públicas, Direito fundamental.

\begin{abstract}
The research analyzes four public policies, which are being carried out by the Empresa Brasileira de Correios e Telégrafos (ECT), expanding the service structure. There are four services provided by ECT, studied from the perspective of public policies. The text continues divided into two parts, starting with the construction of a trajectory of public policies, starting from the fundamental law and the frameworks of modern constitutionalism, to arrive at public policies that follow the logic of positivation in legal norms and the presence of the State. And, ending with the analysis of the four services: Community Post Box; Community Post Office Community Post Office; Social Charter and, Banco Postal. Services that were created to meet social inclusion, mainly benefiting people previously without access to postal and banking services. The methodology used bibliographic, documentary and legislation references, of an exploratory nature, with a qualitative approach and a dialectical historical materialistic analytical method. As instruments of analysis the category of densification of the State in the territory and the concepts of fundamental law and public policies. In the midst of the study of the recent period of the ECT (1990-2017), these four public policies and the goals for the universalization of postal services were found. With the reading of the Annual Public Policy and Corporate Governance Charter (2016-2017), some ECT reports of online access, bibliographies, legislation and other documents, the research base was built. These are policies of recent institutionalization, from the last quarter of the 1990s to the present, in the process of improvement and incorporation.
\end{abstract}

Keywords: Postal Services, Public Policy, Fundamental Right.

\footnotetext{
${ }^{1}$ Mestre Desenvolvimento Socioeconômico PPGDSIUNESC. gabrielcmazon@ gmail.com

${ }^{2}$ Economista. Professor permanente do Programa de Pós-Graduação em Desenvolvimento Socioeconômico da Universidade do Extremo Sul Catarinense PPGDSIUNESC.
} 


\section{INTRODUÇÃO}

O presente artigo se propõe a descrever e analisar quatro serviços da Empresa Brasileira de Correios e Telégrafos (ECT), que foram instituídos, estruturados, reestruturados e passam a fazer parte de um projeto de universalização. Foram criados na segunda metade da década de 1990 e primeira metade dos anos 2000 . O objetivo é a partir da análise destes serviços, tratados como políticas públicas, entender como a ECT se tornou central nessas políticas. A metodologia foi de pesquisa foi exploratória, de abordagem qualitativa, com método de análise materialista histórico dialético, que considera os acontecimentos no seu lugar, no tempo e suas contradições. As fontes foram bibliográficas (teses, dissertações e artigos), documentais (relatórios da ECT) e legislação relacionada o setor postal e aos assuntos relacionados durante a construção do artigo. Como instrumento analítico, foram empregados os conceitos de políticas públicas e serviço social postal. Serviço social postal é um conceito que deve permear a pesquisa em vias de ser consolidado como instrumento analítico, definindo os serviços postais prestados por empresa pública, que possibilitam a emancipação de todas as camadas sociais de maneira indiscriminada em todos os povoamentos, incluindo os serviços que os agentes privados não conseguem ou não tem interesse de fornecer. Como em alguma medida, todos os serviços se mostram inviáveis para alguma região, principalmente, nas tarifas reduzidas que a Empresa Brasileira de Correios e Telégrafos opera para integrar todas as regiões. No esforço de definição de um conceito que se realiza em todo o território brasileiro, incorporando múltiplas estruturas, técnicas e serviços, é que se propõe a denominação de estrutura social postal a toda estrutura de interferência direta da ECT.

$\mathrm{O}$ artigo se dividirá em duas partes. Na primeira parte o texto aborda o direito fundamental e o surgimento do constitucionalismo moderno (social), com as constituições Mexicana de 1917 e de Weimar de 1919, prosseguindo com uma contextualização sobre o que são políticas públicas e o que motiva sua criação. Do direito fundamental e constitucionalismo social, dá-se sequência explicando as motivações das políticas públicas e o papel do Estado, como responsável pela institucionalização e pelo orçamento. Assim, da mesma forma, os direitos fundamentais segundo Comparato (2003), são positivados em norma jurídica, o que difere dos direitos humanos que são universais, independente de uma aprovação ou não. $\mathrm{Na}$ segunda parte, onde os serviços postais aparecem como via de políticas públicas, as políticas trabalhadas são: Banco Postal (Portaria n ${ }^{\circ}$ 588, de 04 de outubro de 2000), Caixa Postal Comunitária (Portaria $\mathrm{n}^{0}$ 141, de 28 de abril de 1998), Agência de Correio Comunitária 
(Instrução Normativa $\mathrm{n}^{\mathrm{o}} 1$ do Ministério das Comunicações, de 14 de dezembro de 2000) e Carta Social (Portaria $\mathrm{n}^{\circ}$ 553, de 12 de dezembro de 2011). Também a própria universalização dos serviços postais (Portaria No 566, de 29 de dezembro de 2011), que se utilizou e estimulou algumas dessas políticas. Conclui-se que os serviços postais têm reforçado seu enraizamento na sociedade (como um bem público), por meio da execução de políticas públicas, que utilizam a estrutura postal, sobretudo, com o franco processo de integração nacional e inserção social, que a universalização dos serviços em pequenos núcleos populacionais proporcionou. Dessa forma, os Correios prestam um serviço indispensável, principalmente, para a parcela da população que está mais desassistida pelo Estado, estando em todos os municípios brasileiros, tem um peso que não pôde ser ignorado e com uma estrutura flexível.

\section{DIREITO FUNDAMENTAL, POLÍTICAS PÚBLICAS E O SOCIAL}

O conceito de políticas públicas surgi no Brasil com a "Constituição Cidadã” de 1988, portanto, para se construir uma trajetória de longa duração sobre políticas de cunho social é necessário retroceder na história, nomeando da forma como era tratado evitando anacronismos. Inicia no século XIX, com leis isoladas que atendiam a demandas sociais especificas, mas tem como marco o constitucionalismo moderno no século $\mathrm{XX}$, que reconhecia os direitos fundamentais das sociedades pelas quais se responsabilizava, no estabelecimento de normas legais para a organização social, não necessariamente direitos naturais inerentes ao ser humano. Portanto, direitos fundamentais podem ser conceituados como essencialidades asseguradas em sede constitucional, direitos positivados na base legal do Estado, que rege as demais normas jurídicas, sendo reflexo da sociedade e refletindo seu disposto. A Constituição de um país, nesse contexto, já é considerada a porta de entrada para entender sua sociedade. Como um reflexo da sociedade a qual ela busca organizar e reproduzir, na medida que é reforçada como norma jurídica "mãe", da qual as demais leis deverão derivar e respeitar suas concessões e negações. Isso significa, que para ampliar os direitos sociais numa população, é preciso que eles constem ou sejam permitidos pela Constituição. Segundo Fábio Konder Comparato (2003), o que difere os direitos fundamentais dos direitos humanos, é que o primeiro exige um reconhecimento jurídico constitucional, que é independente de uma vontade universal, enquanto que os direitos humanos não precisam de reconhecimento, por serem autônomos em relação a uma ordem jurídica a favor ou contra, no entanto, na prática mais universal do que um direito fundamental. 
A ideia de direitos fundamentais, teve início na teoria contratualista, que remete aos séculos XVII e XVIII, numa realidade onde tínhamos um Estado de seu soberano, onde um indivíduo era soberano de um povo e submetia-os a sua vontade. Os direitos fundamentais nesse contexto, buscaram um soberano que exerceria domínio em submissão ao respeito a tais direitos, ou seja, uma submissão do Estado aos indivíduos. Ocorreu assim a transição do Estado de um soberano, para o Estado liberal, constitucionalizando estes direitos, sobretudo, os ditos direitos de primeira dimensão (direito à liberdade), que seriam uma forma de blindar a população. Já no século XX, com a complexificação das economias nacionais, o advento da Primeira Guerra Mundial, a ocorrência de alguns conflitos internos, vemos serem gestadas duas Constituições consideradas as percursoras do constitucionalismo moderno, preocupado com o social, a Constituição Mexicana de 1917 e a Constituição Alemã de 1919 (conhecida como Constituição de Weimar). Não dá para auferir a inexistência de preocupações sociais anteriores, no entanto, não se tem conhecimento desse registro em Constituição, embora pudesse haver registros de tais direitos ou de sua permissão em outros dispositivos jurídicos, como leis menores. (PINHEIRO, 2006) O respeito à dignidade humana, que é considerado fundamental para a formação de organizações sociais, não pode ser dissociada da democracia. Uma resposta democrática a governos autoritários, no México (1917) e na Alemanha (1919) levaram a uma modernização do Estado, em prol de liberdades sociais, que se positivaram em normas, configurando um "constitucionalismo moderno".

“A Carta Política mexicana de 1917 foi a primeira a atribuir aos direitos trabalhistas a qualidade de direitos fundamentais, também as liberdades individuais e os direitos políticos (Arts. 52 e 123) ". Seguindo a mesma linha, a Constituição de Weimar de 1919, e as convenções da OIT (Organização Internacional do Trabalho), no mesmo ano (COMPARATO, 2003). A Constituição Mexicana de 1917, foi promulgada para satisfazer as reivindicações revolucionárias, num sentido institucionalizado e regulamentado. Uma revolução que inicia em oposição à ditadura do Presidente Porfírio Díaz (1876-1911), em 1911, sendo seguida de alternâncias entre líderes que renunciaram ou foram assassinados de um lado, enquanto do outro, líderes revolucionários do Norte (Pancho Villa e Pascual Orozco) e do Sul (Emiliano Zapata) tencionavam por suas reivindicações. Passadas as alternâncias, assumiu o fazendeiro Francisco Madero, de volta do exilio nos Estados Unidos, descumprindo suas promessas de reforma agrária. Os revolucionários saem então vitoriosos, dividindo-se em dois grupos: constitucionalistas (Carranza e Alváro Obregón) e convencionalistas (Emiliano Zapata e Pacho Villa). Uns pela substituiçãoไreforma da Constituição de 1857 e outros pelas reformas da 
convenção de Alguascaliente (1914), respectivamente. Para frear Zapata, que já estava devolvendo terras aos indígenas, distribuindo outras aos camponeses e criando créditos agrícolas no Sul, Carranza como presidente, promulga a Constituição de 1917. Ela possui os traços do constitucionalismo social, dispondo quanto "ao direito a vida (direitos de primeira dimensão), ou seja, de uma vida digna, com saúde, assistência social e lazer (segunda dimensão) e um meio ambiente equilibrado (terceira dimensão) ", se entendendo isso como, "em relação ao indivíduo $\left(1^{\mathrm{a}}\right)$, ou a coletividade nacional $\left(2^{\mathrm{a}}\right)$, em face de toda a comunidade $\left(3^{\mathrm{a}}\right)$ " (PINHEIRO, 2006).

A primeira Constituição alemã, conhecida como a Constituição de Weimar, foi um dos resultados da Primeira Guerra Mundial (1914-1918), sofrendo inicialmente uma resistência em função do contexto em que foi construída. Não houve tempo para que as ideias ali instituídas fossem amadurecidas, causando um desconforto para a população, recém-saída de uma guerra, depois de quatro anos, que foram o suficiente para deixar marcas de mutilação física e emocional. As soluções a essa altura tendiam muito mais ao extremismo, enquanto o novo texto constitucional trazia valores sociais. Em novembro de 1918, o Keise Guilherme II tentando manter sua dinastia, frente a instabilidade, abdicou em favor de seu filho Príncipe Max Baden, buscando ganhar tempo como imperador. No mesmo ano, é proclamada a república na Baviera em 8 de novembro, os grupos radicais de esquerda se instalam e Baden abdica em favor dos revoltosos, declarando um de seus líderes chanceler em Berlim. Nos últimos dias de novembro é promulgada uma nova lei eleitoral e são convocadas eleições para representantes do congresso. Formado o novo congresso, no início do ano de 1919, por ampla maioria é convocada uma nova assembleia nacional constituinte. Em meio a um sangrento massacre que se seguiu em Berlim, os líderes esquerdistas Karl Liebknecht e Rosa Luxemburgo foram capturados e executados. Com o enfraquecimento da esquerda, única capaz de resistir a influência comunista soviética, o movimento socialista alemão foi para as urnas abatido demais para atrair o eleitorado da classe média, contra a direita totalitária. Os socialistas acabam ganhando com pouca margem, a assembleia se instala e Hugo Preuss fica encarregado do texto, influenciado por ideias "pré-medievais, com exigências socialistas ou liberais-capitalistas da civilização industrial”. O texto final é então aprovado em 31 de julho de 1919, pouco após a ratificação do tratado de Versales, no dia 9 de julho do mesmo ano, impondo duras restrições a recuperação da economia alemã. (COMPARATO, 2003)

Assim, ficou claro que os direitos sociais e fundamentais não foram concebidos de "boa vontade", passando desde o início por processos conflituosos e mesmo traumáticos, frutos por 
exemplo, de tempos de guerra e recente pós-guerra. São práticas institucionalizadas, que passam a fazer parte da estrutura do Estado, que passa a ter a responsabilidade de tomar a frente de políticas sociais. A iniciativa pode ou não vir dele, enquanto que a normatização é por sua conta e a sustentação do orçamento da política. Surgem assim as políticas públicas, do Estado para a sociedade, cada uma com sua especificidade. Com o tempo novas demandas se tornam direitos fundamentais reconhecidos, assim como sociedade e a economia se complexificam, surgindo novas necessidades básicas da sociedade no seu lugar e no seu tempo, no que a iniciativa privada por suas características não é capaz ou não tem interesse de prover.

No campo de estudos sobre políticas públicas existem pelo menos duas vertentes, polarizadas entre Europa e Estados Unidos, onde o primeiro trabalha com políticas públicas como um dever do Estado, reflexo do estado de bem-estar social, enquanto o segundo considera uma opção de cada governo, na sua representatividade (SOUZA, 2007). Na área do direito, as políticas públicas vêm sendo estudadas buscando vencer a esterilização do direito, sobretudo, público no sentido de organização da sociedade. Isso no Brasil, que ainda carece de definir os limites do público e do privado, entre direito privado e administrativo. Ainda o conceito de público-não-estatal, que expressa uma organização paralela ao Estado, considerado um espaço gerador de políticas públicas. Esses espaços podem ser representados pelos conselhos, que inclusive estão previstos na Constituição de 1988, como forma de permitir a participação mais ativa da sociedade, na discussão de suas demandas sociais, orientando o direcionamento dos investimentos públicos. Em alguns casos temos conselhos estabelecidos por leis, como o caso da Lei Orgânica da Saúde, Assistência Social, Estatuto da Criança e Adolescente e outros. Como pode-se perceber, todas as políticas públicas são estabelecidas por normas jurídicas, passando a ser um direito, devendo refletir a vontade coletiva do público alvo (BUCCI, 2001). Talvez por isso e pela proximidade com a área do direito, que muitos dos principais autores encontrados tratando do tema coincidiram em ser dessa área, inclusive em alguns trabalhos deixando quase aparente essa leitura.

As políticas públicas são ações planejadas do poder público, que orientam procedimento em consonância com a sociedade, para articular Estado e sociedade, na execução de projetos. Os recursos para financiar tais políticas são públicos, aplicados diretamente ou através de renúncia fiscal (isenções). Elas refletem relações de poder político tanto na elaboração quanto na implementação, distribuindo e redistribuindo benefícios à custos socializados. $\mathrm{Na}$ elaboração, cabe a definição de quem tomará a decisão, com exigências que podem ter suas "raízes" em conflitos. É importante definir a quem serve a política pública, para que não seja 
confundida com uma política puramente governamental, sendo que nem toda política governamental é pública. Com o passar dos anos e o surgimento de novas demandas, que estão sendo regulados elou fomentados por essas políticas, dar publicidade e chamar a sociedade para discutir se tornou indispensável (TEIXEIRA, 2002). Apesar das diversas definições sobre o conceito, no tratamento em torno do tema e sua funcionalidade, existe um sentido em comum, de olhar para os governos. Os governos como um território que conflita visões e interesses divergentes e convergentes, com especificidades. A perspectiva básica que norteia todo o processo de tais políticas, é o de que o todo é mais importante, não sendo uma soma das partes, mas um interesse em comum que deve ser sanado. Por mais que tenhamos políticas públicas distintas, com suas intencionalidades e atendendo segmentos da sociedade heterogênea, são políticas que se institucionalizam de forma homogênea, para atender a população para a qual foi planejada (SOUZA, 2007).

Visam atender sobretudo, a grupos marginalizados que passam a serem assistidos por meio destas, de cunho direcionado. O direcionamento da política pode ser entendido tanto em relação a grupos, quando em relação a demandas, diferindo em cada caso quanto a sua abrangência. Também, temos políticas de desenvolvimento, por exemplo, de geração de emprego e renda e políticas focadas em amenizar conflitos sociais, mesmo dentro de grupos hegemônicos. Nesse ponto, é importante entender que há dependência em relação a orientação política de cada governo. Na visão liberal existe uma clara oposição a universalização, já que o indivíduo tem maior autonomia e é responsável por si mesmo. No Estado Liberal, a política pública é um resíduo. O Estado de bem-estar social, já é resultado de governos socialdemocratas, que tem um entendimento de que as políticas públicas devem ser mais abrangentes, como um dever do Estado de assistir a sua população. Em resposta a recessão de alguns Estados, pela incapacidade de sustentar algumas políticas, seja por insuficiência de recursos ou por opção política, ganha força uma visão neoliberal. Essa visão negativada, em prol de um equilíbrio financeiro, é legitimada pela situação econômica, disseminando um discurso que responsabiliza o aumento de sua participação no orçamento, pela recessão econômica. (TEIXEIRA, 2002).

São primeiro positivadas em norma jurídica, para que seja considerada sua implantação legal. Isso representa a criação de uma instituição, que consiste no estabelecimento de certas regras e na criação de um orçamento próprio ou de estrutura para disputar um outro orçamento, no qual se encaixe. Com um orçamento essas políticas se tornam um território em disputa, onde a forma de gestão desses recursos estabelece uma forma mais ou menos concentrada de representatividade, que irá decidir seus usos. As próprias decisões são sempre dotadas de uma 
condicionalidade, especifica de cada caso. Nesse sentido, empresas públicas já fazendo parte da estrutura estatal servem a materialização e execução de tais políticas, instrumentos na mão dos governos. Algumas dispondo do fornecimento de serviços essenciais a população, como os serviços de comunicação, saúde, educação, estrutura logística básica, entre outros.

\section{INTEGRAÇÃO NACIONAL, INCLUSÃO SOCIAL E POLÍTICAS PÚBLICAS: ECT}

A Empresa Brasileira de Correios e Telégrafos está presente em todos os 5.570 municípios brasileiros, cumprindo seu papel que não poderia ser definido de outra forma, se não o de agente de integração nacional. Isso, somado as metas de universalização e à inclusão bancária (Banco Postal), se utilizando da adaptabilidade intrínseca a sua estrutura e o alcance populacional, se transformou num dos maiores veículos de execução e subsidio a políticas públicas e ações de responsabilidade social. Uma resposta multissecular a demandas governamentais e sociais. Uma longa permanência como bem público, enraizado na vida cotidiana da população, que colabora no fortalecimento de uma estrutura social postal.

O que atualmente regula os serviços postais é Lei $n^{\circ} 6.538$, de 22 de junho de 1978, que definiu os direitos e obrigações da ECT. Em seu texto define os serviços de sua atribuição e como se compõem seus recursos, de forma concisa definindo ao que se propõe. No seu artigo $3^{\circ}$, assegura a continuidade dos serviços, mediante o cumprimento de boas práticas, estabelecidas pelo Ministério das Comunicações. Nos artigos $5^{\circ}$ e $6^{\circ}$ garante o sigilo de correspondência, e mesmo quando por motivo previsto em lei, for permitido a sua abertura, é garantida a não publicidade do conteúdo. É garantido no seu artigo 15 e 16, a manutenção do endereçamento e a sua edição sem fim comercial, e nos artigos 20 e 21 exige que os condomínios disponibilizem caixa para recebimento de objetos e correspondências, individuais para cada morador, e o mesmo pedido é feito para quem reside em casas, também para hospitais, bancos, instituições de ensino, entre outros, em todos os endereços atendidos por serviço de entrega domiciliar. Por fim, as atividades postais que são atribuições da União, explorada em regime de monopólio pelos Correios, estão no artigo $9^{\circ}$, como segue:

I - recebimento, transporte e entrega, no território nacional, e a expedição, para o exterior, de carta e cartão-postal; II - recebimento, transporte e entrega, no território nacional, e a expedição, para o exterior, de correspondência agrupada: III - fabricação, emissão de selos e de outras fórmulas de franqueamento postal. (BRASIL, 1978) 
É vital ter conhecimento desse trecho da lei, para esclarecer que o monopólio postal se refere a serviços específicos de correspondência, salvaguardados do regime concorrencial, entendidos como um dever do Estado em benefício de toda a população. Estes serviços são deficitários em quase toda a extensão da estrutura postal, assim a maior parte da estrutura em si, com raras exceções em relação a regiões metropolitanas e cidades de maior porte. Enquanto isso, os serviços de entrega de encomendas, que são desde sua implementação os que trazem maior retorno financeiro aos Correios, são submetidos ao regime concorrencial. Já não é recente a tensão entre grupos de interesse para privatização da estrutura postal de inúmeras maneiras e atacando o "monopólio dos Correios". Uma importante disputa jurídica recente, colocou em revisão a Lei $n^{\circ}$ 6.538, de 22 de junho de 1978, sobretudo seu Artigo no 42 que estabelece punição quando ignorada, tendo sido submetida a voto no Supremo Tribunal Federal, no julgamento da Arguição de Descumprimento de Preceito Fundamental (ADPF) no $4617 \mathrm{DF}^{3}$. Segundo texto da ADPF 46, os interessados alegavam que havia um descumprimento, em relação aos princípios de livre concorrência e a livre iniciativa, previstos na Constituição Federal.

O Artigo $n^{\circ} 42$, objeto central do julgamento, segue abaixo:

\section{VIOLAÇÃO DO PRIVILÉGIO POSTAL DA UNIÃO}

Art. 42 - Coletar, transportar, transmitir ou distribuir, sem observância das condições legais, objetos de qualquer natureza sujeitos ao monopólio da União, ainda que pagas as tarifas postais ou de telegramas.

Pena: detenção, até dois meses, ou pagamento não excedente a dez dias-multa. (BRASIL, 1978)

Ainda consta veiculado na página de notícias do STF, que foram definidos com maior clareza os casos em que a penalidade é válida, definiram os conceitos de correspondência e do que já estava claro, quanto ao compartilhamento do conceito de encomendas, quanto as suas responsabilidades. Isso significa, que se manteve o monopólio no que concerne aos serviços de correspondências, deixando os serviços de encomendas ao sabor da concorrência (SUPREMO TRIBUNAL FEDERAL, 2009). Além dos ataques ao monopólio postal, por leitura equivocada ou proposital, por parte do interlocutor, tem-se encontrado referências que criticam a lei que regula os serviços postais, dizendo ser caduca em relação a Constituição Federal (CF) de 1988,

\footnotetext{
${ }^{3}$ Julgamento da Arguição de Descumprimento de Preceito Fundamental (ADPF), $n^{\circ}$ 46, que julgou uma revisão da Lei $\mathrm{n}^{\circ}$ 6.538, de 22 de junho de 1978, que regula os serviços postais, em descumprimento do Artigo 42 da referida lei, pela Empresa Brasileira de Correios e Telégrafos, também a sua consonância em relação a Constituição Federal de 1988. ADPF 46, na integra, disponível em: $<$ http://redir.stf.jus.br/paginadorpub/paginador.jsp?docTP=AC\&docID=608504> Acesso em: Julhol2018.
} 
por ser datada de 1978, anterior a lei magna. Se aproveitam do entendimento dubio de alguns trechos do texto, sendo o principal, o Artigo $5^{\circ}$, inciso IX da $\mathrm{CF}$, onde diz que "é livre a expressão da atividade intelectual, artística, científica e de comunicação, independentemente de censura ou licença”. Nessa justificativa, fica clara a intenção de usar por analogia a liberdade assegurada de cada pessoa, para aplicar aos serviços públicos, como se esses ferissem as liberdades dos indivíduos por lhes guardar alguma exclusividade, em atribuições do Estado, no que considera estratégico. Retomando, quando fazemos a leitura de outros dois Artigos da CF, que se referem aos serviços postais explicitamente, podemos observar que a lei que regula os serviços postais, está longe de estar ultrapassada. No "Art. 21, do que compete à União, inciso $\mathrm{X}$, manter o serviço postal e o correio aéreo nacional", enquanto no "Art. 22, do que compete privativamente à União legislar, inciso V, o serviço postal".

Depois de superar inúmeras tentativa de privatização, desmonte e mitigação de recursos, vencendo o julgamento citado, é institucionalizada a universalização dos serviços postais e da qualidade, estipulando metas. Dessa forma o ECT saiu fortalecida do processo, reforçando sua interiorização. As normativas do Ministérios das Comunicações, Portaria MC nº 566, de 29 de dezembro de 2011 e Portaria MC nº 6.206, de 13 de novembro de 2015 (alterada parcialmente pela Portaria $\mathrm{n}^{\circ}$ 6.194, de 27 de dezembro de 2016), que na maioria de seus textos se repetem, tem em comum uma intenção que coincide no crivo da norma:

Art. $1^{\circ}$ Estabelecer as metas para a universalização e de qualidade dos serviços postais básicos a serem cumpridas pela Empresa Brasileira de Correios e Telégrafos - ECT. $\S 1^{\circ}$. Entende-se por universalização dos serviços postais básicos o acesso de toda pessoa física ou jurídica, independentemente de sua localização ou condição socioeconômica, aos serviços discriminados no $\S 2^{\circ}$ deste artigo.

$\S 2^{\circ}$. Consideram-se serviços postais básicos o recebimento e entrega de: I - carta e cartão postal, simples ou registrados, sem valor declarado; II - impresso simples ou registrado, sem valor declarado; e III - encomenda não urgente, sem valor declarado. (MINISTÉRIO DAS COMUNICAÇÕES, 2011; 2015)

As metas de universalização e qualidade, visam aumentar o percentual da população atendida pelos serviços postais e em prazos menores. Ainda, em 07 de março de 2018, foi aprovada a Portaria MCTIC $n^{\circ} 1.203$, que sendo baseada na Portaria $n^{\circ}$ 6.194, de 27 de dezembro de 2016, buscando atender a meta de qualidade, estabeleceu a DDA (Distribuição Domiciliar Alternada), reorganizando o padrão de entrega. Com a DDA, os dias uteis de entrega passam a ser alternados, mesmo para as localidades atendidas com o serviço diário, salvo a exceção de entrega de objetos com contrato de entrega diferenciado, justificando que isso diminuiria a sobrecarga dos trabalhadores, conseguindo melhorar o atendimento domiciliar 
(MINISTÉRIO DAS COMUNICAÇÕES, 2018). Essas metas foram para o Plano Plurianual (PPA 2016-2019), onde passaram a fazer parte do orçamento, transformando as metas em indicadores. Assim, no prazo de vigência do PPA 2016-2019, 100\% dos distritos com população igual ou superior a 500 habitantes devem ser atendidos com serviço postal, pelo menos 97,5\% atendidos com entrega postal externa e com qualidade na prestação dos serviços postais básicos (EMPRESA BRASILEIRA DE CORREIOS E TELÉGRAFOS, 2018). Na execução do que foi estabelecido, estão sendo utilizados dois serviços, de aprovação anterior: Caixa Postal Comunitária e Agências dos Correios Comunitária. Também servindo a projetos de universalização, o serviço Banco Postal traz a possibilidade de inclusão financeira de significativa parcela até então excluída dos bancos tradicionais, e a aproximação com algumas parcelas vulneráveis da população se dá pela solicitação da Carta Social.

\subsection{Caixa Postal Comunitária}

A Portaria MC n n $^{\text {141, de }} 28$ de abril de 1998, instituiu o Serviço de Caixa Postal Comunitária (CPC), descrevendo o serviço e os critérios para sua instalação. Tinha intenção de sanar a falta de serviço de entrega domiciliar ou entrega irregular, em algumas localidades, considerando uma população mínima de 500 habitantes, num raio de distância em relação ao endereço de instalação, de três quilômetros em zona rural e quinhentos metros em perímetro urbano. Aprovada a portaria, foram estipulados também os primeiros passos para sua instalação (MINISTÉRIO DAS COMUNICAÇÕES, 1998). A demanda latente por serviços de maior qualidade e menor custo, para mais uma etapa de ampliação da estrutura postal no território, deixou evidente o problema da desorganização do endereçamento, o que dificulta muito o trabalho de entrega domiciliar. Ainda que fosse ampliado o quadro de trabalhadores dos Correios e lhes desse mais preparo, para lidar com o dia-a-dia do seu trabalho, ficando mais eficientes, isso não resolveria esse problema (ESCOLA NACIONAL DE ADMINISTRAÇÃO PÚBLICA, 1999).

Nos espaços urbanos, o acelerado processo de ocupação e surgimento de periferias, impôs a realidade de endereçamento desorganizadas, ficando as correspondências retidas nas agências, esperando para serem retiradas. Só que na maioria das vezes, essas agências se encontram bastante afastadas do local de moradia do destinatário do objeto, o que dificultava sua retirada. Com a melhoria no padrão de renda dessa parcela da população, que passou a consumir, se intensificou o uso do serviço de encomendas, pedindo uma solução, para atender melhor essa camada mais pobre. A primeira Caixa Postal Comunitária foi instalada em Curitiba, 
no ano de 1996, nos dois anos seguintes outros 49 pontos foram instalados. A instalação exige o envolvimento da comunidade, para que seja estabelecido um local seguro, que pode ser por exemplo, em escolas e postos de saúde, em instituições públicas ou ao resguardo de pessoa jurídica. Exige o envolvimento da comunidade, sendo assinada a parceria com a associação de moradores, que se responsabiliza. Os Correios arcam com os custos de instalação e operação do serviço. (ESCOLA NACIONAL DE ADMINISTRAÇÃO PÚBLICA, 1999).

O serviço é similar ao de caixas de assinatura, que são encontrados nas agências postais convencionais, que são receptáculos com chave, que são disponibilizadas para quem tem interesse, mediante a contratação do serviço. A principal diferença em relação ao serviço convencional em agências é a terceirização da responsabilidade pela conservação e guarda das caixas, que ocorre em endereço não disponibilizado pela empresa, que garante a chegada dos objetos até elas. Sendo normatizado em 1998, este serviço teve maior difusão em função das periferias, solucionando o problema da desordem dos endereços, levando os objetos e correspondências próximas ao destinatário. Mas não podemos desconsiderar a importância do serviço nas comunidades rurais, ou vilas isoladas, que podem apresentar menor representatividade numérica e ao mesmo tempo ter maior centralidade do que na periferia. A maior facilitação ao acesso a bens e serviços, atualização das informações e o caráter simbólico de se fazer presente o Estado na comunidade, por meio do estabelecimento de uma via de comunicação.

\subsection{Agência Postal Comunitária}

Pela Instrução Normativa $n^{\circ} 1$, de 14 de dezembro de 2000, do Ministério das Comunicações, foram normatizados os "procedimentos para implementação de Agências de Correios Comunitária pela Empresa Brasileira de Correios e Telégrafos (ECT)”. Esse dispositivo legal, referenciado em normas anteriores, inclusive na já citada Portaria de instituição do serviço de CPC. O serviço tem intensão de viabilizar ao menos a prestação de serviços postais básicos, de acordo com o que a norma define, em localidade menores, com população igual ou superior a quinhentos habitantes, bem como "em áreas urbanas onde predomine o interesse social e a exploração econômica de serviços postais não se mostre viável". A operação se dando por ente público e privado, mediante convenio, onde a ECT arca com uma parcela dos recursos e prevendo contrapartida do operador terceirizado

\footnotetext{
${ }^{4}$ Relato de Experiência de Luís Carlos Werner, da Diretoria Regional do ParanálECT. Publicado pela Escola Nacional de Administração Pública, pelo Concurso Inovação na Gestão Pública Federal, 1999.
} 
(MINISTÉRIO DAS COMUNICAÇÕES, 2000). Segundo dados mais recentes, do Relatório de Administração dos Correios - Exercício de 2017, no ano de 2017 contabilizavam 4.217 Agências de Correios Comunitária (AGC) (ECT, 2017). Em 2016, foi criado o instrumento de Acordo de Cooperação Técnica (ACTs) para localidades fora da meta, onde os custos foram assumidos pelas prefeituras, e durante esse ano 107 ACTs foram assinados em oito estados (Relatório de Gestão ECT, 2017). Os Correios como um serviço público, incumbido de operar em um território vasto e de povoamento irregular, nas localidades mais afastadas, muitas vezes é o único vestígio da presença do Estado. As AGC's vêm para ser mais uma alternativa a ampliação da estrutura postal, deixando claro o compromisso firmado e auxiliando na universalização dos serviços postais básicos, dentro de um padrão de qualidade estipulado pelas Portarias já citadas.

Nesse contexto, convencidos da responsabilidade do serviço postal para o desenvolvimento das pequenas localidades, como meio de comunicação e integração entre as comunidades, a ECT firma convênios com os Executivos Municipais interessados. A barreira a instalação é o Art. 19F5, $\S 3^{\circ}$ da Constituição Federal, que impede o estabelecimento de tal convênio com entes inadimplentes com a Seguridade Social, no entanto, entendendo certas limitações da norma, em 21 de julho de 2011 é aprovada a Lei ${ }^{\circ} 12.423$, que flexibiliza a norma para casos excepcionais, de ocorrências de catástrofes que impossibilitem atender à exigência (MEDEIROS, 2014). Quanto ao convenio, é importante ter conhecimento Lei $\mathrm{n}^{\circ} 8.666$, de 21 de junho de 1993, que versa sobre licitações e contratos da Administração Pública e dá outras providências, sendo o Correio um serviço público e submetido a norma, enfatizamos os Arts. $1^{\circ}$ e $2^{o}$ que valem para este caso. Nestes dois artigos fica claro que os convênios serão estabelecidos dentro da Administração Pública, entre órgãos públicos, pertencentes as três: União, estados e municípios (BRASIL, 1993). Quanto ao texto da Instrução Normativas nº1, que instituiu o serviço de Agência de Correio Comunitária, ele cita uma parceria com ente público ou privado, este ente privado segundo Alessandra Costa Medeiros (2014), advogada da ECT, se refere a empresa privada sem fins lucrativos, que opera respaldada pela administração pública municipal. Uma espécie de terceirização da operação, em responsabilidade do Executivo Municipal, que teve a iniciativa.

\subsection{Banco Postal}

Buscando a inclusão financeira de pequenas comunidades, pela Portaria $n^{\circ} 588$, de 04 de outubro de 2000, o Ministério das Comunicações em Artigo $1^{\circ}$ instituiu o Serviço Financeiro 
Postal Especial, denominado Banco Postal, a ser prestado pela ECT. O serviço sendo direcionado a prestação de serviços bancários básicos, em todo território nacional, com ênfase aos municípios desassistidos por tal serviço, "como instrumento de inserção social”. No seu texto, estipula duas metas, sendo até o final do ano de 2001 estabelecido em mil agências, enquanto ao final do ano de 2003 estará em todos os municípios, desassistido de serviço bancário. Segue os serviços aos quais está autorizado:

\begin{abstract}
Art. $4^{\circ} \mathrm{Na}$ qualidade de correspondente, a ECT poderá prestar um ou mais dos seguintes serviços, em comum acordo com as instituições parceiras: I - recepção e encaminamento de propostas de abertura de contas de depósito à vista, a prazo e de poupança; II - recebimentos e pagamentos relativos a contas de depósitos à vista, a prazo e de poupança, bem como aplicações e resgates em fundos de investimento; III - recebimentos e pagamentos decorrentes de convênios de prestação de serviços mantidos pelo banco parceiro, na forma de regulamentação em vigor; IV - execução ativa ou passiva de ordens de pagamento em nome do banco parceiro; $\mathrm{V}$ - recepção e encaminhamento de pedidos de empréstimos e de financiamentos; VI - análise de crédito e cadastro; VII - execução de cobrança de títulos; VIII - outros serviços de controle, inclusive processamento de dados, das operações pactuadas; e IX - outras atividades, a critério do Banco Central do Brasil. Parágrafo único. A prestação dos serviços referidos nos incisos I e II deste artigo depende de prévia autorização do Banco Central do Brasil. (MINISTÉRIO DAS COMUNICAÇÕES, 2000)
\end{abstract}

A instalação do Banco Postal, para ser melhor analisada, exige que saibamos ser um serviço longe de ser isolado no mundo. Países como França, Alemanha, Japão e outros, já possuem serviços dessa natureza. Existe ainda, uma determinação da ONU e do Banco Mundial, incentivando a abertura de bancos postais. Segue no trecho abaixo, retirado do Projeto de Lei $n^{\circ} 6.413$, de 2002, que pedia o uso de transporte de valores por lotéricas e agências dos Correios:

"Nos últimos anos, o Banco Mundial tem estimulado os bancos postais por serem entendidos como um mecanismo auxiliar na tarefa de inclusão social. Para a ONU, igualmente, os bancos postais são considerados como cruciais para o micro-crédito, a micro-poupança e o próprio desenvolvimento das populações mais carentes e mais isoladas no mundo". (CAMARA DOS DEPUTADOS, 2002)

O Banco Postal funciona como um prestador de serviços financeiros, tendo autorização do Conselho Monetário Nacional e do Ministério das Comunicações, passa a operar como um correspondente bancário, impedido de constituir um banco próprio. Iniciou suas operações em 2002, e até o ano de 2010 já havia aberto aproximadamente 10 milhões de contas, chegando a 95\% dos municípios, onde nos anos de 2009 e 2010 obteve receitas de aproximadamente R\$ 200 milhões (ECT, 2010). Para o ano de 2017, foram abertas 96 mil contas correntes, com mais de 148 milhões de transações, concessão de $\mathrm{R}$ \$ 248,1 milhões em crédito e rendimento de R\$ 281 milhões referentes ao exercício corrente (ECT, 2017). Até o ano de 2010, o Banco Postal era correspondente do Bradesco, tendo sofrido no ano de 2011 uma dura concorrência em processo licitatório, com o Banco do Brasil, onde perdeu mando, então o Banco Postal passou 
a ser correspondente do Banco do Brasil. Ainda, por proposta apresentada durante o governo Lula e com autorização obtida no governo Dilma, no ano 2013 a ECT incorpora os serviços financeiros em seu estatuto social e anunciando no mesmo ano, a criação de sociedade igualitária entre ECT e Banco do Brasil no Banco Postal. (TEIXEIRA, 2013)

\subsection{Carta Social}

Dentro de uma estratégia dos Correios, como estrutura de Estado, atrelada ao caráter social impresso pelos governos Lula e Dilma, e alinhados as convenções e determinações internacionais, vem estabelecendo políticas públicas e sociais, num sentido de promover a integração nacional e a inclusão social. A própria ECT, por determinação da Lei $n^{\circ} 13.303$, de 30 de junho de 2016, com foco no artigo 8, incisos I e VIII, divulgou nos anos de 2017 e 2018 , sua Carta Anual de Políticas Públicas e Governança Corporativa, referente ao ano anterior. Portanto, faz todo sentido buscar nos serviços postais um caráter fomentador de políticas públicas, principalmente em momento propicio. Mais um serviço criado antes desse movimento de universalização, é o serviço de Carta Social, reestruturados em 2011 e 2012, que busca alcançar a camada da sociedade de menor renda.

A Carta Social é uma modalidade de carta correspondência, que foi criada pela Portaria $\mathrm{n}^{\circ} 245$, de 09 de outubro de 1995, onde também foram definidas as modalidades de Carta Não Comercial e Carta Comercial, sendo a Carta Social pouco detalhada, mencionando no início do texto da Portaria, a intensão de colaborar para o benefício social e desenvolvimento econômico. Ficava assegurado o peso máximo de dez gramas, a necessidade de mencionar seu tipo na carta e o tratamento igual ao da Carta Não Comercial (MINISTÉRIO DAS COMUNICAÇÕES, 1995). Então que a Portaria $n^{\circ} 553$, de 12 de dezembro de 2011 substitui a norma anterior, dedicada ao serviço de Carta Social, que coloca dentro da modalidade de Carta Não Comercial, cuja cobrança era de $\mathrm{R} \$ 0,75$ por carta de até 20 gramas. (site institucional do Governo Federal, 2011) Por fim, normatizada pela Portaria $n^{\circ} 469$, de 16 de novembro de 2012, revoga a Portaria anterior, passando a definir como destinada a cidadãos cadastrados no Programa Bolsa Família do Governo Federal, indivíduos que se encontram penados ou custodiados, brasileiros ou estrangeiros, em qualquer parte do território nacional. A finalidade da medida é de colaborar para a inclusão social. (MINISTÉRIO DAS COMUNICAÇÕES, 2012) A Carta Social em momento de distribuição é trata como a Carta Não Comercial, especialmente para os beneficiários do Programa Bolsa Família do Governo Federal, a tarifa cobrada será de apenas R 0,01 pelo selo, permitindo cartas de até 10 gramas (MINISTÉRIO DO 
DESENVOLVIMENTO SOCIAL, 2015). Explicitamente o serviço tem caráter de inclusão social, sobretudo, a camada da sociedade de menor renda, que consiste nos beneficiários do Programa Bolsa Família, quando institui tarifa simbólica de um centavo, sendo um estímulo ao uso desse serviço postal básico de carta simples envelopada.

\section{CONCLUSÃO}

Concluiu-se que os serviços postais têm reforçado seu enraizamento na sociedade (como um bem público), por meio da execução de políticas públicas, que utilizam a estrutura postal, sobretudo, com o franco processo de integração nacional e inserção social, que a universalização dos serviços em pequenos núcleos populacionais proporcionou. Dessa forma, os Correios prestam um serviço indispensável, principalmente, para a parcela da população que está mais desassistida pelo Estado, estando em todos os municípios brasileiros, tem um peso que não pôde ser ignorado e com uma estrutura flexível. Isto se encaixa aos quatro serviços postais apresentados, ressaltando a inclusão bancárialfinanceira fomentada pela criação e disseminação do Banco Postal. São serviços sociais postais que buscam dar a possibilidade de acesso a bens e serviços, para a fração da população que não desperta o interesse das empresas privadas, por ser economicamente inviável, apresentar condições que sinalizam demora do retorno de investimentos após instalação, sem garantia de exclusividade de uso da infraestrutura criada ou apontando para uma margem reduzida ou instável. Por isso, tomando para si os riscos de instalação e espera pela amortização dos investimentos, a empresa púbica como um "braço" do Estado sai na frente, pelo entendimento dos gestores e do governo de que o investimento é necessário independente de déficits.

Os serviços de Caixa Postal Comunitária e Agência de Correio Comunitária, ganharam novo folego por conta da meta de universalização, que é um desafio imposto pelo objetivo de atender aos pequenos povoados com pelo menos quinhentos habitantes. Tamanha foi a adesão e as solicitações dos municípios, que pediram uma alternativa para povoamentos ainda menores, do Acordo de Cooperação Técnica, para instalar serviços postais em povoados com menos de quinhentos habitantes, com apoio técnico de operação da ECT e custeado pelo orçamento municipal. Os serviços postais financeiros, que o Banco Postal que iniciou como correspondente bancário, em seguida internalizado em seu estatuto social, já alcançou largo percentual da população e do território, onde não havia tal serviço. Um projeto de inclusão 
social e bancárialfinanceira, com resultado superavitário, estimulando a economia das penas localidades.

A Carta Social que atende aos beneficiários do Programa Bolsa Família, aos penados e aos brasileiros e estrangeiros em situação vulnerável, salta aos olhos a cada marco legal, se aproximando mais da população de menor renda. Os beneficiários do Bolsa Família, tem regime de tarifa diferenciado dos demais, deixando clara a opção pela inclusão social. Uma política pública social, que vem para acessar uma parcela significativa da população que não é assistida por serviços similares públicos ou privados. Um direito que se tornou fundamental, a inclusão social, positivado em norma constitucional, que sobreviveu aos obstáculos, atendendo a população independente de um pré reconhecimento universal, embora houvesse alguns pedidos, que fizeram parte da elaboração da política.

\section{REFERÊNCIAS}

BUCCI, Maria Paula Dallari. Buscando um Conceito de Políticas Públicas para a Concretização dos Direitos Humanos. In: BUCCI, Maria Paula Dallari et alli. Direitos humanos e políticas públicas. São Paulo, Pólis, 2001. 60p. (Cadernos Pólis, 2)

Disponível em: <http://www.polis.org.br/uploads/831/831.pdf> Acesso em: Julhol2018.

COMPARATO, Fábio Konder. A afirmação histórica dos direitos humanos. São Paulo: Saraiva, 3 ed. rev. e ampl., p. 342, 2003. Disponível em:

<http://www.academia.edu/10113444/A_afirma\%C3\%A7\%C3\%A3o_hist\%C3\%B3rica_dos_ direitos_humanos_-_COMPARATO_Fabio_K> Acesso em: Julhol2018.

EMPRESA BRASILEIRA DE CORREIOS E TELÉGRAFOS. Caixas Postais

Comunitárias. Relato de Experiência: Luís Carlos Werner. Brasília: ENAP - Concurso Inovação. p. 4. 1999. Disponível em:

<http://repositorio.enap.gov.br/bitstream/1/955/1/024_98\%20CAIXAS\%20POSTAIS\%20CO MUNIT\%C3\%81RIAS.pdf> Acesso em: Julhol2018.

. Relatório de Administração. Brasília, DF, p. 5, 2010. Disponível em:

<https://www.correios.com.br/sobre-os-correios/a-empresa/publicacoes/relatorios/relatoriosde-administracao/pdf/RelatorioAdministracao_2010.pdf> Acesso em: Julhol2018.

Relatório de Administração. Brasília, DF, p. 16, 2017. Disponível em:

<https://www.correios.com.br/sobre-os-correios/a-empresa/publicacoes/relatorios/relatoriosde-administracao/pdf/RA_2017_assinado.pdf> Acesso em: Julhol2018.

Prestação de Contas Ordinária Anual: Relatório de Gestão do Exercício de 2016. Brasília, DF: ECT \MCTIC, p. 258, 2017. 
ESCOLA NACIONAL DE ADMINISTRAÇÃO PÚBLICA. Experiência: Caixas Postais Comunitárias. Relato de Experiência: Luís Carlos Werner. MClECT\DR-Paraná. Brasília: ENAP. p. 4, 1999. Disponível em:

<http://repositorio.enap.gov.br/bitstream/1/955/1/024_98\%20CAIXAS\%20POSTAIS\%20CO MUNIT\%C3\%81RIAS.pdf> Acesso em: Julhol2018.

PINHEIRO, Maria Cláudia Bucchianeri. A Constituição de Weimar e os direitos fundamentais sociais: A preponderância da Constituição da República Alemã de 1919 na inauguração do constitucionalismo social à luz da Constituição Mexicana de 1917. Brasília, DF: Senado Federal, a. 43, nº 163, p. 26, 2006. Disponível em:〈http://www2.senado.leg.br/bdsf/bitstream/handle/id/92449/Pinheiro\%20Maria.pdf> Acesso em: Julhol2018.

MEDEIROS, Alessandra Costa. A função social das Agências de Correios Comunitários e a flexibilização do Artigo 195, $\S 3^{\circ}$ da Constituição Federal. Brasília, DF: Revista de Estudo de Direito Postal da ECT. p. 16, 2014. Disponível em: $<$ https://www.correios.com.br/sobre-os-correios/a-empresa/revista-de-estudo-de-direitopostal-da-ect/edicoes-anteriores/pdf/2013-e-2014/1alessandra2014.pdf> Acesso em: Julho\2018.

SOUZA, Celina. Estado da arte da pesquisa em políticas públicas. p. 65-86. In: HOCHMAN, Gilberto; ARRETCHE. Marta; MARQUES, Eduardo (Orgs.). Políticas públicas no Brasil. Rio de Janeiro: Fiocruz, 2007. Acesso em: Julhol2018. Disponível em: $<$ https://books.google.com.br/books?hl=pt-

BR\&lr=\&id=iBP0AgAAQBAJ\&oi=fnd\&pg=PA65\&dq=Estado+da + arte + da + pesquisa + em + p ol\%C3\%ADticas+p\%C3\%BAblicas+Pol\%C3\%ADticas+p\%C3\%BAblicas+no+Brasil\&ots=a F9R9MDg3b\&sig=f5UwJv9KTBDGCdIOnS57Vdj2xBs\&redir_esc=y\#v=onepage \&q=Estado $\% 20 \mathrm{da} \% 20$ arte $\% 20 \mathrm{da} \% 20$ pesquisa $\% 20 \mathrm{em} \% 20$ pol\%C3\%ADticas $\% 20 \mathrm{p} \% \mathrm{C} 3 \%$ BAblicas $\% 20 \mathrm{P}$ ol\%C3\%ADticas\%20p\%C3\%BAblicas\%20no\%20Brasil\&f=false >

TEIXEIRA, E. Celso. O Papel das Políticas Públicas no Desenvolvimento Local e na Transformação da Realidade. DHnet: Direitos Humanos na Internet. p. 11. 2002. Disponível em: <http://www.dhnet.org.br/dados/cursos/aatr2/a_pdf/03_aatr_pp_papel.pdf> Acesso em: Julhol2018.

TEIXEIRA, Tadeu Gomes. Os Correios em transformação: reestruturação, organização do trabalho e políticas de gestão do trabalho (1994-2011). (Tese) Campinas ISP: Unicamp, p. 303, 2013. Disponível em:

<http://repositorio.unicamp.br/bitstream/REPOSIP/280162/1/Teixeira_TadeuGomes_D.pdf> Acesso em: Julhol2018.

\section{Legislação:}

BRASIL. Constituição (1988). Constituição da República Federativa do Brasil. Brasília, DF: Senado Federal: Centro Gráfico, 292 p. 1988. Disponível em: <http://www.planalto.gov.br/ccivil_03/constituicao/constituicao.htm> Acesso em: Julhol2018. 
Lei no 6.538, de 22 de junho de 1978. Brasília, DF: Presidência da República. 1978. Disponível em: <http://www.planalto.gov.br/ccivil_03/Leis/L6538.htm> Acesso em: Julhol2018.

Lei no 8.666, de 21 de junho de 1993. Brasília, DF: Presidência da República. 1993. Disponível em: <http://www.planalto.gov.br/ccivil_03/Leis/18666cons.htm> Acesso em: Julhol2018.

Lei no 13.303, de 30 de junho de 2016. Brasília, DF: Presidência da República, 2016. Disponível em: <http://www.planalto.gov.br/ccivil_03/_ato20152018/2016/lei/113303.htm> Acesso em: Julhol2018.

CÂMARA DOS DEPUTADOS. Projeto de lei. $\mathbf{n}^{\mathbf{0}}$ 6.413, de 2002. Câmara dos Deputados: Comissão de Segurança Pública e Combate ao Crime Organizado. p. 3, 2002. Disponível em: $<$ http://www.camara.gov.br/proposicoesWeb/prop_mostrarintegra?codteor=255151\&filename $=\mathrm{EMC}+1 / 2004+\mathrm{CFT}+\% 3 \mathrm{D} \% 3 \mathrm{E}+\mathrm{PL}+6413 / 2002>$ Acesso em: Julho\2018.

MINISTÉRIO DAS COMUNICAÇÕES. Portaria no 245, de 09 de outubro de 1995. Ministério das Comunicações. p. 2, 1995. Disponível em: $<$ https://www.correios.com.br/sobre-os-correios/a-empresa/legislacao/portarias-einstrucoes/pdf/Portaria_245_09_10_1995.pdf> Acesso em: Julhol2018.

Portaria $\mathbf{n}^{\mathbf{0}}$ 588, de 04 de outubro de 2000. Ministério das Comunicações. Diário Oficial da União: 05 de outubro de 2000. p. 3. 2000. Disponível em: $<$ https://www.correios.com.br/sobre-os-correios/a-empresa/legislacao/portarias-einstrucoes/pdf/Portaria_588_04_10_2000.pdf> Acesso em: Julhol2018.

Instrução Normativa no 1 , de 14 de dezembro de 2000. Ministério das Comunicações. p. 3, 2000. Disponível em: <https://www.correios.com.br/sobre-os-correios/aempresa/legislacao/portarias-e-instrucoes/pdf/Instrucao_Normativa_1_14_12_2000.pdf> Acesso em: Julhol2018.

Portaria n 566, de 29 de dezembro de 2011. Ministério das Comunicações. p. 4, 2011. Disponível em: <http://www.consultaesic.cgu.gov.br/busca/dados/Lists/Pedido/Attachments/416934/RESPOS TA_PEDIDO_53850001203201563_Anexo2_Portaria\%20MC\%20566_2011.pdf> Acesso em: Julhol2018.

. Portaria no 469, de 16 de novembro de 2012. Ministério das Comunicações. (Publicado no Diário Oficial da União de 19 de novembro de 2012). Brasília, DF: Ministério da Justiça (comunicado ao sistema penitenciário, CuritibalPR). p. 4. 2012. Disponível em: <http://www.depen.pr.gov.br/arquivos/File/selosocial.pdf> Acesso em: Julhol2018.

Portaria $\mathbf{n}^{0}$ 6.206, de 13 de novembro de 2015. Ministério das Comunicações. Diário Oficial da União: 02 de dezembro de 2015. p. 41-43. 2015. Disponível em: $<$ http://pesquisa.in.gov.br/imprensa/jsp/visualiza/index.jsp?data=02/12/2015\&jornal=1\&pagi na=43\&totalArquivos=84> Acesso em: Julhol2018. 
Portaria no 6.194, de 27 de dezembro de 2016. Ministério da Ciência, Tecnologia, Inovação e Comunicação. Diário Oficial da União: 30 de dezembro de 2016. p. 187-187. 2016. Disponível em:

<http://www.consultaesic.cgu.gov.br/busca/dados/Lists/Pedido/Attachments/557714/RESPOS TA_PEDIDO_99923000634201774\%20Prt_MCTIC_n_6194_30dez2016.pdf> Acesso em: Julho\2018.

Portaria n⿳ 1.203, de 07 de março de 2018. Ministério da Ciência, Tecnologia, Inovação e Comunicação. Diário Oficial da União: 08 de agosto de 2018. p. 7-7. 2018. Disponível em:

<http://www.mctic.gov.br/mctic/opencms/legislacao/portarias/Portaria_MCTIC_n_1203_de_ 07032018.html> Acesso em: Julhol2018.

\section{Outras fontes:}

GOVERNO DO BRASIL. Tarifa R\$ 0,01 para Carta Social será restrita a beneficiários do Bolsa Família. (site institucional do Governo Federal) Publicado em: 14 de dezembro de 2011, editado em 22 de dezembro de 2017. Disponível em:

<http://www.brasil.gov.br/cidadania-e-justica/2011/12/tarifa-r-0-01-para-carta-social-serarestrita-a-beneficiarios-do-bolsa-familia> Acesso em: Julhol2018.

MINISTÉRIO DO DESENVOLVIMENTO SOCIAL. Carta Social. Publicado em: 29 de julho de 2015. Disponível em: <http://mds.gov.br/assuntos/cadastro-unico/o-que-e-e-paraque-serve/carta-social> Acesso em: Julhol2018.

SUPREMO TRIBUNAL FEDERAL. STF mantém monopólio dos Correios para correspondências pessoais (atualizada). Brasília: Notícias STF. Quarta-feira, 05 de agosto de 2009. Disponível em:

<http://www.stf.jus.br/portal/cms/verNoticiaDetalhe.asp?idConteudo=111512> Acesso em: Julhol2018.

\section{SUPREMO TRIBUNAL FEDERAL. Arguição de Descumprimento de Preceito}

Fundamental 46. Brasília, DF: STF, p. 208, 2009. Disponível em:

$<$ http://redir.stf.jus.br/paginadorpub/paginador.jsp?docTP=AC\&docID=608504> Acesso em: Julho\2018. 